\title{
Learners' awareness of their emotions and their engagement with mathematics tasks in a mathematics club
}

\section{Jeanne-Mari Frenzel}

Department of Curriculum Studies, Faculty of Education, Stellenbosch University, Stellenbosch, South Africa jmdups@gmail.com

https://orcid.org/0000-0001-9762-2145

\section{Christine Erna Lampen}

Department of Curriculum Studies, Faculty of Education, Stellenbosch University, Stellenbosch, South Africa ernalampen@sun.ac.za

https://orcid.org/0000-0003-4379-9242

\section{Karin Brodie}

School of Education, University of the Witwatersrand, Johannesburg, South Africa

Karin.Brodie@wits.ac.za

https://orcid.org/0000-0002-3959-7401

(Received: 22 January 2019; accepted: 2 August 2019)

\section{Abstract}

The role and influence of learners' emotional experiences on their engagement or disengagement while working on mathematics tasks is under-researched in South Africa. Cognitive education research points increasingly to the importance of emotional awareness in cognitive activities and learning situations. In this paper, we describe how Grade 8 learners gained more awareness of their emotions during tasks by using an emotions lexicon as they participated in a mathematics club. We used observations, questionnaires, and interviews to gather data about the learners' awareness of their emotions and their engagement and perseverance with mathematics tasks. Our results indicate that awareness of emotions through access to an emotions vocabulary has a positive influence on individual learners' motivation and mathematical engagement as well as on group engagement, but we found, too, that the expected social consequences of engagement in emotionally risky classrooms may vitiate the personal gains.

Keywords: emotions, engagement, motivation 


\section{Introduction}

Research in South Africa has yet to grapple with the emotional experience of learning mathematics in classrooms. ${ }^{1}$ Elsewhere, work on emotions tends to focus on general dispositions toward the learning environment, such as finding school or mathematics fun or not, while not much is known about how particular emotional experiences during learning influence learners' academic engagement (Wang \& Degol, 2014). Research about interventions in learners' emotional states during learning is also scarce (see Schukajlow, Rakoczy, \& Pekrun, 2017). Internationally, cognitive education researchers are increasingly pointing to emotional awareness as an important factor that enables learners to harness emotional information in order to influence cognitive activities (Grewal \& Salovey, 2005).

Emotional experience is key to shaping learners' beliefs about what they are capable of in mathematics (Sheldrake, Mujtaba, \& Reiss, 2015) and is indicated as an essential component of motivation (Fredericks, Blumenfeld, \& Paris, 2004) and engagement (Wang \& Degol, 2014). Engagement is viewed as a metaconstruct comprised of three main constructs, namely cognitive or academic engagement, behavioural engagement, and emotional engagement. If learners are supported to make sense of their emotional cognition as emotions experienced during cognitive practice (Hannula, 2002), they are more likely to regulate not only their emotions, but also their behavioural and cognitive engagement. Such regulation of personal emotions and behaviour has the potential to lead to shared engagement and awareness of the group's emotional state.

In this paper we describe how learners, using a tool that provided an emotions lexicon, began to identify, name, and relate their emotions to possible causes stemming from their task engagement. We describe how negative engagement patterns of individuals, and of the group, changed as learners gained more emotional awareness. The opportunity to work with learners' emotional awareness emerged when we searched for ways to intervene with disengaged learners who displayed disruptive behaviour in a mathematics club. We designed an intervention aimed at promoting the cognitive emotional awareness of the club learners specifically through helping them to describe their emotions as they were working on mathematics tasks. In this paper, we ask the following research question: In what way does awareness of cognitive emotions help learners in a mathematics club to engage behaviourally and cognitively while working on mathematics tasks?

\section{The mathematics club}

In 2016, a mathematics club was established at an historically disadvantaged high school. The aim of the club was to build learners' confidence in themselves as problem-solvers in mathematics. The school chose which learners would participate on the basis of their results, which ranged between $40 \%$ and $60 \%$ in mathematics at the beginning of Grade 8 . The study focussed on 19 learners who attended regularly throughout the year. The learners could be

We searched multiple data bases using the keywords mathematics, South Africa, emotions, affect and motivation but not a single article was returned. 
described as being at risk. They came from poor and gang-ridden communities where often the need to survive and make an income was prioritised above the need for education.

The club met weekly on Saturdays to work on problem-based tasks. We planned for opportunities for learners to engage by providing hands-on challenging tasks, by listening to learners' responses to the tasks, and by establishing feedback conversations based on their reasoning and our clear expectations that they should share their thinking. The correct answer was not the primary goal of the problems, but, rather, it was working mathematically, which entails figuring out whether and why answers are valid.

The club curriculum was low-stakes in that performance was not assessed, time pressure was eased, and success was formulated and celebrated as individual progress - something learned on a particular day. The learners worked in self-designated groups of between two and five, with constant free-flow interaction among peers and with the club facilitators.

There were four facilitators - a mathematics education lecturer and three mathematics education post-graduate students. Their role was to engage learners in discussions of their mathematical thinking and problem-solving in relation to the specific task, rather than to provide direct instruction. For many learners, simple calculations were challenging and they tended to disengage early, claiming that they knew the answer once some calculation had been performed. The facilitators would then generate further discussion by asking "Why?" or "What if ?" questions that raised the cognitive demand of the task.

During the initial club sessions, we observed that although learners were willing and ready to engage at the beginning of each session, a point would soon be reached where they would disengage and become disruptive. They would complain of hunger and tiredness despite having been given food and displaying high levels of energy in their disruptive behaviour. We considered that this behaviour and lack of engagement was a facade for something elsecognitive stress. In other words, we speculated that once the tasks reached a certain level of cognitive demand that the learners struggled to meet, they would experience negative emotions which they did not recognise, could not verbalise, or did not have the strategies to deal with. Hunger and tiredness might be proxies_feelings they could explain, act on, and defend.

\section{Conceptual framing: Emotions, motivation, and engagement}

Learners' enacted emotions provide a window into their reasons for deciding to engage or disengage in mathematics tasks. Our initial experience of the learners' emotions suggested a theoretical focus on emotions, motivation, and engagement as three aspects of learning mathematics that have a constant dynamic interaction with each other. In this paper emotions refer to the cognitive emotions learners reported feeling and directed at their struggle with a mathematics task. We draw on Whiting (2011) who has argued that emotion is directed towards an intentional object (such as a mathematics task) even though the complex source of 
the emotion is not clear. Although there are many factors influencing emotions, and thus motivation and engagement, learners can have stable patterns of emotional reactions in similar situations, such as working on mathematics tasks (Hannula, 2012). Motivation refers to the willingness of the learners, individually and as a group, to persist with the mathematics task. Engagement refers to the observable behavioural action of staying on task and the nature of the participation in the mathematics task, that is, whether learners invest cognitive energy in their work.

The notion of emotional cognition supports the idea that emotions and motivation are directly linked (Hannula, 2006), suggesting that the motivation behind engagement or disengagement can be better understood if we pay attention to the emotional experiences of the learners. A learner's motivation to engage at task level is influenced by three components. These are 1) the emotions felt during a mathematics task, 2) the general emotion associated with mathematics, and 3) the expected social consequences of engaging in a task based on the appraisal of similar prior events (Hannula, 2002, 2006). Should learners experience negative cognitive emotions and lack sufficient coping strategies, they are more likely to lose motivation to engage with the task. This is exacerbated by previous negative emotional experiences of doing mathematics.

The relationship between engagement, motivation, and emotions is theorized through Jacobs, Fehres, and Campbell's (2012) three components of emotions: physiological responses; behavioural reactions; and self-reports of subjective experiences. In our study physiological responses are those responses pertaining to their bodies that learners used to justify their decision to (dis)engage. For example, a learner who was struggling with the mathematics task and feared embarrassment may have claimed a desperate need of the bathroom in order to avoid engaging in feedback or discussion. Similarly, as observed in our club, a learner may have given hunger or tiredness as a reason for not being able to concentrate. We do not think that the learners made these claims falsely, but, rather, that they may have experienced the same emotional discomfort as when they were hungry or tired. Behavioural reactions refer to observable displays of emotions such as facial expressions, utterances, and physical and noisy disruption of the work of others. Self-reports of subjective experiences refer to the narratives of the learners - the stories they tell themselves and us about how they feel and how these feelings affect their motivation to (dis)engage. Disengagement can spread through a class, notably through behavioural responses. Figure 1 illustrates our view of these relationships. 


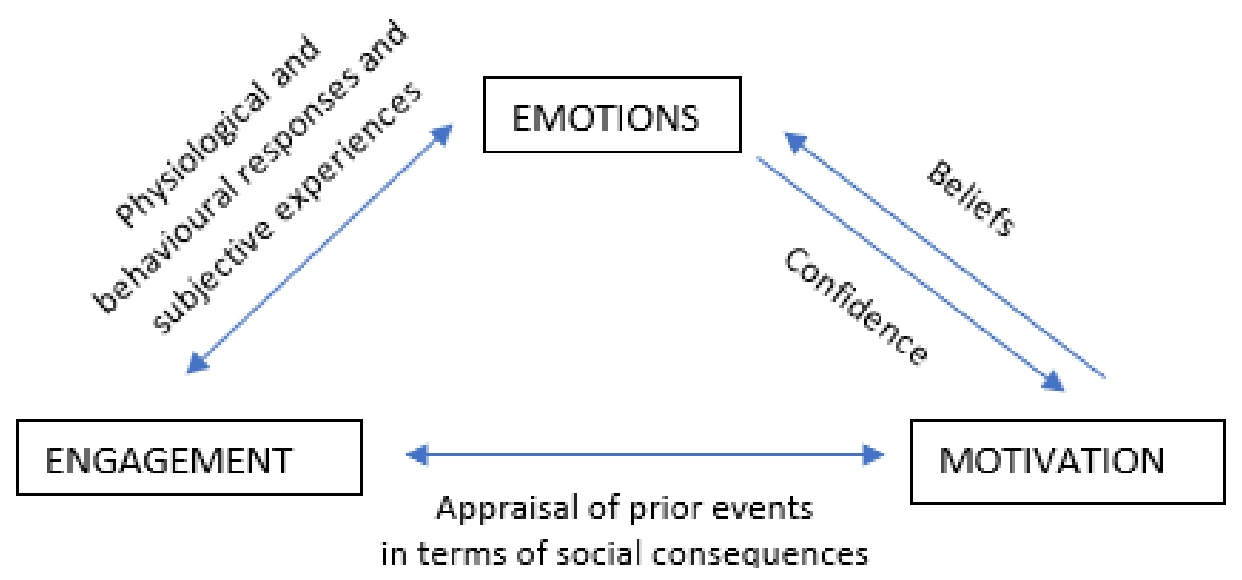

Figure 1: Interactions between emotions, motivation, and engagement with mathematics tasks

These relationships were all observable in our club setting. We could observe learners' physiological and behavioural responses, and, through learner narratives, we were also able to learn much about their beliefs about, and confidence in, their mathematical abilities.

\section{Data collection}

Given our observations of the learners' enacted emotions during the club sessions, we decided to work more explicitly with their emotions as part of their task activity and developed a study exploring the extent to which we could guide them to name and engage their emotions explicitly while working mathematically.

Our intervention began with asking the learners to fill in a structured self-report sheet about their emotional experiences during a task. We asked the learners to name their emotion at three intervals during the task engagement: at the beginning; in the middle when the lowthreshold solution was likely reached; and at the end. They were also requested to write down a reason for their naming of that specific emotion, and, after the completion of the task, to write a short reflective note on their change in emotional state. The facilitators made field notes about observed emotional displays and the engagement of the learners.

It became clear that the learners did not have the emotional vocabulary to describe their feelings and they were unable to identify the source of their emotions. Learners would write down the same words repeatedly or copy words used by their peers. In some cases, they asked the facilitators to provide them with various emotions words, or used words that are not descriptive of emotions, such as "understand" or "nice." The learners did not provide any reasons for the emotions they named and their reflective paragraphs were notes of thanks to the facilitators. It was evident that if we were to understand the emotions at play during the mathematics tasks, we would need to assist the learners to find words that accurately describe their emotions, without identifying the emotions for them. 
Plutchik's Emotions Wheel (Plutchik, 2001) was adapted for this purpose. The original design of this tool named a large number of emotions, many of which we believed the club learners would not understand. So we simplified the tool to make it more relevant to our study, and included specific emotions identified through research in mathematics education, such as fear, disgust, and interest (Hannula, 2002), frustration, annoyance, worry, relief, and nervousness (Op 't Eynde, de Corte, \& Verschaffel, 2006), boredom, anxiety, enjoyment, anger, shame, pride, and hopefulness (Kim, Park, \& Cozart, 2014; Schukajlow \& Rakoczy, 2016). We also included a column with possible suggestions as to why learners feel the way they do. Learners were also encouraged to write their own emotion words and reasons if the lexicon ${ }^{2}$ did not provide options that were to their satisfaction.

The data from the self-report sheets was supplemented with field notes based on our observation of behaviours traditionally associated with certain emotions (such as crying out as a sign of excitement) as well as verbal cues given by learners (such as reporting the desire to give up). The data was also supplemented by semi-structured interviews with individual learners, during which they were asked to reflect on certain club sessions and elaborate on their emotional state during specific tasks. The five learners who were interviewed were selected based on the combination of their responses on the self-report sheets over four tasks, and their willingness to participate in an interview. We focused on learners who indicated dramatic emotional changes or learners who had, in a particular session, indicated emotions outside of their usual responses. Data from questionnaires about beliefs and experiences of mathematics at school was used to supplement the analysis.

In conducting the study, we adhered to all the ethical protocols of the University and the Western Cape Education Department. Learners were informed of their right to withdraw from the club or the study at any point and to refuse to answer any questions, should they wish to. In the interviews, we tried to put learners at ease, indicating that we wanted to hear their perspectives, and asked them specifically if we could use the information in our research reports. In all writings from the project pseudonyms are used and the school's anonymity is protected.

\section{Data Analysis}

The data was analysed using a two-way table, based on the conceptual framework for the study. First, the data was sorted according to Hannula's (2002) three components: emotions experienced during a task; the general emotions associated with mathematics; and the expected social consequences of participating based on the appraisal of prior events. This data was then analysed in relation to Jacobs, Fehres, and Campbell's (2012) three components of emotions: physiological responses; behavioural reactions; and self-reports of subjective experiences. The table below shows the framework for data analysis, with the various data collection methods as they contribute to each cell in the matrix. Three cells are not filled in because there was not sufficient data to formulate any claims for these.

2 The lexicon is provided as an appendix. 
Table 1: Framework for data analysis

\begin{tabular}{|c|c|c|c|}
\hline & $\begin{array}{l}\text { Awareness of cognitive } \\
\text { emotions during the tasks }\end{array}$ & $\begin{array}{l}\text { General emotions } \\
\text { associated with } \\
\text { mathematics }\end{array}$ & $\begin{array}{l}\text { Appraisal of prior events } \\
\text { in terms of social } \\
\text { consequences }\end{array}$ \\
\hline Physiological responses & Facilitators' field notes & & \\
\hline Behavioural reactions & Facilitators' field notes & & $\begin{array}{l}\text { Facilitators' field notes and } \\
\text { interviews }\end{array}$ \\
\hline $\begin{array}{l}\text { Self-reports of subjective } \\
\text { experiences }\end{array}$ & $\begin{array}{l}\text { Emotions lexicon and } \\
\text { interviews }\end{array}$ & $\begin{array}{l}\text { Interviews and } \\
\text { questionnaires }\end{array}$ & Interviews \\
\hline
\end{tabular}

We discuss our findings in each vertical category of data in relation to each of the horizontal categories.

\section{Findings}

\section{Awareness of cognitive emotions during the tasks}

We observed an increase across the four tasks in the variation of descriptive words used by the learners to identify their emotions. During Task 1 there were at most eight different responses with no reasons given for the emotions named. Of the 16 learners, 11 used the word "happy" to describe their initial feelings. The facilitators explained word meanings to learners to help them make the link between their experience and the words. During Task 2, there were 12 different responses, with 12 different reasons and two deviations from the emotions lexicon, indicating greater emotional awareness and individual regard for their named emotions. For example, during Task 2, a learner stated that he felt "nervous" because he was "struggling to determine the algorithm of the sum." This was a very task-specific response and was a deviation from those suggested on the lexicon.

During Tasks 3 and 4 learners still often compared their chosen words with each other but now such comparisons were accompanied by a discussion of their experiences and subsequent word choices. We observed that the learners displayed increased independent reflection on their emotions, taking time to think about which emotions and reasons they would report to the facilitators. Their reported emotional states increasingly corresponded with our observations and interpretations of their emotional states.

\section{Physiological responses during the tasks}

There was a large decrease in the demands for breaks and the verbalisation of hunger and tiredness from the second task on. During tasks prior to the intervention, learners struggled to maintain engagement before the break and rarely managed to get back on task after a break. Once they started to reflect on their emotions with the help of the emotions lexicon, they 
were staying on task for an hour and a half, and sometimes even the full two hours. On occasion we had to call on them to conclude and go for their sandwiches before the canteen closed. Furthermore, learners increasingly voiced their physiological needs, such as hunger or tiredness, more effectively by explicitly informing us of their needs and addressing them quickly and then continuing with the task. During the interviews, the learners stated that during later tasks, their hunger did not distract them from their work. It would appear that the learners had gained an awareness of their feelings which led to more effective regulation of these physiological needs.

\section{Behavioural reactions and self-reports during the tasks}

Self-reports of learners' emotional states with the use of the emotions lexicon was accompanied by increased engagement, increased on-task discussions among learners, the desire to work more independently of the facilitators, and "figur[ing] things out themselves." We also observed a decreased spread of unruly behaviour among the groups. Even from the first monitored task to the second, their written reports showed a one-fifth increase in reports of pride in their work and their ability to persist.

\section{General emotions associated with mathematics}

\section{Self reports}

We did not observe learners in their school classrooms but conducted a questionnaire and interviewed them about their views on mathematics. At the commencement of the club and this study, most of the learners reported positive emotions associated with mathematics. Of the learners $78 \%$ agreed with the statement that "mathematics is interesting," 58\% reported mathematics as being enjoyable in high school, while $23 \%$ of the learners had no opinion regarding the enjoyment of mathematics.

In interviews at the end of the year, the learners' general emotions toward mathematics were attributed to their interaction with their teacher rather than the actual mathematics content. All five learners who were interviewed stated that they "liked math" as a subject but that the teacher presented the content poorly and therefore they could not enjoy the subject as they had in primary school. Two learners stated frustration as an emotion associated with mathematics, because even though they felt they understood the work and knew what to do, they always "got the answers wrong and [didn't] know why." Three learners reported negative feelings associated with mathematics, stemming from the belief that the teacher treated certain learners with more privilege and care than others and would "give you bad marks if he did not like you."

During these interviews the learners used words they had been exposed to in the emotions lexicon to describe their feelings associated with mathematics in the school setting. They also freely offered reasons for their emotions. None of the learners referred to the club or the facilitators when talking about their feelings about mathematics. To them mathematics referred solely to the school subject and how it was presented by their class teachers. When 
prompted about how they felt about the club, learners said that they enjoyed everything we did at the club.

\section{Appraisal of prior events in terms of social consequences}

\section{Self-reports}

During the interviews it became clear that affirmation as well as criticism played an important role in whether or not learners wanted to engage in mathematics, in the club as well as in school. Affirmation from facilitators, as well as self-praise through the emotions lexicon, led to the learners reporting increased feelings of pride in their work in the club. However, when prompted to compare working in the club to working in school, the social risk of engagement in a less supportive classroom came into clear focus. One learner argued that in the classroom, where bullying and disruption are part of the classroom culture, it was often easier to disengage and participate in the disruptiveness rather than form part of the minority who engaged and were ridiculed for it. Peers jeering and laughing at one another when someone did not get the correct answer or attempted an ineffective strategy to solve a problem were clear sources of emotional distress and disengagement in the classroom. So past experience informed the learners that future participation in the mathematics class would lead to emotional distress.

\section{Behavioural reactions}

The potential for social-emotional distress was initially carried over into the club, with learners being disruptive and critical of their peers. Despite the facilitators clearly forbidding jeering and ridiculing, such behaviour continued in covert ways and seemed to be socially accepted behaviour among the learners. We worked hard from the beginning to negotiate a supportive classroom culture with the club learners. We asked them to think about a space in which they could learn, and to set the behavioural rules for such a space. They suggested rules like being silent when someone else speaks and respecting each other. Yet the facilitators had to remind them constantly of their own rules and call them to order. As they became more aware of their emotions through naming and giving reasons for them, we noticed a change in the group as a whole: engagement increased and disruptive and demeaning behaviour decreased dramatically with only two learners still acting out from time to time. These learners were increasingly ignored or told off by the others. Learners began to comply with the rules, laughed at one another less, and started to provide emotional support by complimenting one another more, saying, for example, "You can feel proud."

The case of Anthony is a beautiful story. Anthony joined the club but refused to engage, often stating "I don't feel like it" as his reason. It became clear that Anthony was mathematically very weak and also placed a lot of value on his social image and position. The risk of being ridiculed while participating in the mathematics outweighed the desire to learn. This changed in one club activity, which was a hands-on pattern-based task. Anthony thoroughly enjoyed being able to use his hands and did the task very well. He received affirmation from both the facilitators and his peers. As the sessions progressed, Anthony became more willing to 
engage with the mathematics tasks and displayed enjoyment of both the affirmation received, especially from his peers, and the tasks. With manipulatives and pattern-based tasks, he came to be seen as someone who is "good at math" and started to state this of himself as well.

As a summary of the findings, the completed cells of the analytic framework show the changes observed after the implementation of the emotions lexicon.

Table 2: Summary of data analysis

\begin{tabular}{|c|c|c|c|}
\hline & $\begin{array}{l}\text { Awareness of cognitive } \\
\text { emotions during the task }\end{array}$ & $\begin{array}{l}\text { General emotions } \\
\text { associated with } \\
\text { mathematics }\end{array}$ & $\begin{array}{l}\text { Appraisal of prior events } \\
\text { in terms of social } \\
\text { consequences }\end{array}$ \\
\hline Physiological responses & $\begin{array}{l}\text { Decreased reports of hunger } \\
\text { and tiredness, timely } \\
\text { management of physiological } \\
\text { needs }\end{array}$ & & \\
\hline Behavioural reactions & $\begin{array}{l}\text { More sustained engagement, } \\
\text { increased on-task behaviour, } \\
\text { increased desire to persevere, } \\
\text { less disruption of others }\end{array}$ & & $\begin{array}{l}\text { Decreased disruptive } \\
\text { behaviour, increased } \\
\text { compliments to others and } \\
\text { pride in their own efforts }\end{array}$ \\
\hline $\begin{array}{l}\text { Self-reports of subjective } \\
\text { experiences }\end{array}$ & $\begin{array}{l}\text { Increased reports of pride in } \\
\text { their work, voiced opinions } \\
\text { that it is easy to remain } \\
\text { engaged }\end{array}$ & $\begin{array}{l}\text { Focussed on school, not club, } \\
\text { mathematics and social } \\
\text { emotional relations with } \\
\text { teachers }\end{array}$ & $\begin{array}{l}\text { Reports of self-pride and self- } \\
\text { affirmation, believing they can } \\
\text { solve the problems }\end{array}$ \\
\hline
\end{tabular}

\section{Discussion}

Our study confirms that emotional awareness can support cognition and engagement (Hannula, 2002, 2006; Kim et al., 2014; Op 't Eynde et al., 2006). Helping learners to name and identify the source of their negative emotions helped them to acknowledge those emotions and process them so that they were able to engage with cognitive activities. The more this practice of emotional reflection was encouraged, the more positive emotions the learners reported, and the higher the levels of engagement and cognitive tenacity displayed by the learners. This tendency also emphasises the link between emotions, motivation, and engagement as set out in the conceptual framework, and draws attention to the learners' capacities to interrupt their own negative engagement patterns when they become aware of their emotions. We were able to observe the link between emotion and engagement through the learners' physiological responses such as decreased complaints of hunger and through behaviour that became less disruptive and more supportive and constructive. With increased use of the emotions lexicon, learners increasingly prioritised cognitive activity as they gained control of potentially disruptive emotion based prompts and actions. The case of Anthony 
illustrates clearly the link between emotions, motivation, and engagement. Appraisal of prior events had initially hindered Anthony's motivation to engage. A key positive experience changed his beliefs about what he is capable of doing in mathematics. As a result, he showed more positive emotions and engagement. The more he engaged, the more he succeeded, and the more positive emotions and motivation he experienced. Slowly, we watched Anthony's confidence improving as his judgement of his mathematical ability began to improve, feeding his motivation to engage.

Learners' self-reports suggest that they isolated their club experience from mathematics in class. Despite the use of the emotions lexicon, appraisal of prior events in their mathematics classrooms still had learners believing that it was easier to disengage in the mathematics class rather than being ridiculed for what they called "wasted efforts." They expect the class teacher to act as the custodian of an emotionally safe class. In the club they seemed to have valued the fact that ridiculing was expressly forbidden, and that their emotional experiences were acknowledged, while they attributed their unproductive classroom behaviour largely to the class teacher.

Gardee (2019) found that learners were aware of instances when teachers did not care about, or show respect towards, other learners, even when they were not personally experiencing negative behaviour from the teacher. Negative social consequences for the group tend to create negative emotions in relation to mathematics, and may vitiate personal gains in motivation to engage. In the club where we managed the perceived social consequences through maintaining a supportive learning culture, we observed that the learners' use of emotion words to support each other may have promoted the social contagion (Burgess, Ridell, Fancourt, \& Kou, 2018) of positive behavioural and emotional engagement and perseverance that we observed.

The use of the emotions lexicon as a tool for raising emotional awareness was the key intervention in this research project. The lexicon assisted the learners in developing the ability to identify and express their emotions and possible sources in words. The lexicon was used flexibly, allowing learners to create their own reasons and specific emotion words if they felt the need. From early on many learners started to deviate from the lexicon to express their emotions freely. The lexicon also assisted the facilitators to respond to the emotions that learners experienced during a mathematics task, and, as a result, they became aware of how to provide appropriate support to learners in order to promote engagement. What we had previously interpreted blandly as lack of motivation, could be addressed when we understood the underlying emotions (see Hannula, 2006). Furthermore, the facilitators' ability to provide this emotional support also allowed for the development of trust between them and the learners that, in turn, allowed for more open communication in the club, both task related and social. The use of the emotions lexicon and the requirement to reflect on the changes in their emotions post-task, allowed the learners to become aware of the rewards of persistence in problem solving and regulating initial negative emotions. 


\section{Conclusion}

In this paper we have argued that the three aspects of engagement-emotional, cognitive, and behavioural — can be related to emotional awareness while learners are working on tasks. We found that when learners reflected on and learned to name their cognitive emotions during tasks, there was a tendency towards increased engagement and motivation to persist with difficult tasks by individuals, which also spread through the group. This study suggests that there is an urgent need for teachers not only to make mathematics enjoyable, but to support learners in becoming aware of their cognitive emotions during mathematics tasks in order to promote sustained engagement with tasks.

We have described how learners took up and extended a lexicon of emotion words to reflect on and regulate their cognitive emotions. In particular, we have shown how learners' individual awareness of their emotions influenced the group's behavioural engagement positively, possibly through emotional support shown to each other with the use of emotion words to which they were introduced through the use of the lexicon. Although the findings of this study are limited to the context of a small number of learners in a mathematics club and over the span of relatively few mathematics tasks, the findings do suggest that emotions in regular classrooms can be similarly addressed to enhance group behaviour. The reasons behind a lack of motivation and engagement in mathematics classes may be better understood if learners are supported to express their emotional states more accurately, and, thus, to gain awareness of how their emotions fluctuate in relation to specific tasks and different phases in the problem-solving process.

The study also found that creating the room to express emotions in the weekly club setting did not influence the general emotions learners associate with mathematics as a subject. This may be because learners spent more time with mathematics in classrooms, where a less emotionally supportive classroom culture is experienced every day. Thus, our findings suggest that social-emotional influences and classroom climate are important aspects at play in affective experiences, willingness to engage and persist, and, eventually, in learners' expressed dispositions toward mathematics.

Further research is necessary to investigate whether support in expression of emotional states during club problem-solving leads to enhanced cognitive-emotional control in a classroom setting. There may be potential for teachers to provide emotional support to learners that could lead to better social relationships and enhance engagement in the classroom and thus allow for increased engagement and learning.

\section{References}

Burgess, L., Riddell, P., Fancourt, A., \& Kou, M. (2018). The influence of social contagion within education: A motivational perspective. Mind, Brain and Education, 12(4), 164-174. https://doi.org/10.1111/mbe.12178 
Fredericks, J., Blumenfeld, P., \& Paris, A. (2004). School engagement: Potential of the concept, state of the evidence. Review of Educational Research, 74(1), 59-109. https://doi.org/10.3102/00346543074001059

Gardee, A. (2019). Social relationships between teachers and learners, learners' mathematical identities and equity. African Journal of Research in Mathematics, Science and Technology Education, 23(2), 233-243. https://doi.org/10.1080/18117295.2019.1662641

Grewal, D., \& Salovey, P. (2005). Feeling smart: The science of emotional intelligence. Current Directions in Psychological Science, 93(4), 330-339. https://doi.org/10.1111/j.0963-7214.2005.00381.x

Hannula, M. S. (2002). Attitude towards mathematics: Emotions, expectations and values. Educational Studies in Mathematics, 49(1), 25-46. https://doi.org/10.1023/A:1016048823497

Hannula, M. S. (2006). Motivation in mathematics: Goals reflected in emotions. Educational Studies in Mathematics, 63(2), 165-178. https://doi.org/10.1007/s10649-005-9019-8

Hannula, M. S. (2012). Exploring new dimensions of mathematics-related affect: Embodied and social theories. Research in Mathematics Education, 14(2), 137-161. https://doi.org/10.1080/14794802.2012.694281

Jacobs, M., Fehres, P., \& Campbell, M. (2012). Measuring emotions toward wildlife: A review of generic methods and instruments. Human Dimensions of Wildlife, 17, 233247. https://doi.org/:10.1080/10871209.2012.680175

Kim, C., Park, S. W., \& Cozart, J. (2014). Affective and motivational factors of learning in online mathematics courses. British Journal of Educational Technology, 45(1), 171186. https://doi.org/10.1111/j.1467-8535.2012.01382.x

Op 't Eynde, P., de Corte, E., \& Verschaffel, L. (2006). Accepting emotional complexity: A socio-constructivist perspective on the role of emotions in the mathematics classroom. Educational Studies in Mathematics, 63(2), 193-207. https://doi.org/10.1007/s10649006-9034-4

Plutchik, R. (2001). The nature of emotions: Human emotions have deep evolutionary roots, a fact that may explain their complexity and provide tools for clinical practice. American Scientist, 89(4), 344-350. ttps://www.jstor.org/stable/27857503

Schukajlow, S., \& Rakoczy, K. (2016). The power of emotions: Can enjoyment and boredom explain the impact of individual preconditions and teaching methods on interest and performance in mathematics? Learning and Instruction, 33, 117-127. https://doi.org/10.1016/j.learninstruc.2016.05.001 
Schukajlow, S., Rakoczy, K., \& Pekrun, R. (2017). Emotions and motivation in mathematics education: Theoretical considerations and empirical contributions. ZDM Mathematical Education, 49, 307-322. https://doi.org/10.1007/s11858-017-0864-6

Sheldrake, R., Mujtaba, T., \& Reiss, M. J. (2015). Students' intentions to study noncompulsory mathematics: The importance of how good you think you are. British Educational Research Journal, 41(3), 462-488. https://doi.org/10.1002/berj.3150

Wang, M., \& Degol, J. (2014). Staying engaged: Knowledge and research needs in student engagement. Child Development Perspectives, 8(3), 137-143. https://doi.org 10.1111/cdep.12073

Whiting, D. (2011). The feeling theory of emotion and the object-directed emotions.

European Journal of Philosophy, 19(2), 281-304. https://doi.org 10.1111/j.14680378.2009.00384.x 


\section{Appendix: Emotions lexicon used as a tool to promote cognitive emotional awareness}

\begin{tabular}{|c|c|c|}
\hline $\begin{array}{l}\text { Core } \\
\text { Emotion }\end{array}$ & Specific Emotion & Reason why I feel the way I do \\
\hline \multirow{11}{*}{ Happy } & \multirow[t]{2}{*}{ Excited } & I am excited to do mathematics. \\
\hline & & I am excited for this class to end. \\
\hline & \multirow[t]{3}{*}{ Proud } & I am getting the hang of this mathematics. \\
\hline & & Today I tried my best even though I was struggling. \\
\hline & & I know my work is correct and I can prove it. \\
\hline & \multirow[t]{2}{*}{ Enjoyment } & The maths task is fun and easy. \\
\hline & & It is fun to spend time with my friends. \\
\hline & \multirow[t]{2}{*}{ Hopeful } & I believe I will be able to do the math in today's lesson. \\
\hline & & I believe this math task will help me in school as well. \\
\hline & \multirow[t]{2}{*}{ Relieved } & I struggled but I managed on my own in the end. \\
\hline & & The math was easier than I expected. \\
\hline \multirow{8}{*}{ Unhappy } & \multirow{3}{*}{ Irritated/Frustrated } & I am struggling with this math. \\
\hline & & $\begin{array}{l}\text { My friends are bothering me and I am trying to } \\
\text { concentrate on my work. }\end{array}$ \\
\hline & & I want to be done now so that I can go home. \\
\hline & \multirow[t]{2}{*}{ Angry } & I am angry at myself because I keep making mistakes. \\
\hline & & I think this math is a waste of time. \\
\hline & \multirow[t]{3}{*}{ Ashamed } & I am struggling and it makes me feel dumb. \\
\hline & & I don't know how to say what I mean. \\
\hline & & $\begin{array}{l}\text { I feel like I am asking stupid questions but I really } \\
\text { don't understand. }\end{array}$ \\
\hline
\end{tabular}




\begin{tabular}{|c|c|c|}
\hline \multirow{5}{*}{ Worried } & \multirow[t]{2}{*}{ Nervous } & I think the math is going to be difficult. \\
\hline & & $\begin{array}{l}\text { I am scared to share my answers with the class because } \\
\text { I am unsure of them. }\end{array}$ \\
\hline & \multirow[t]{3}{*}{ Anxious } & I am unsure of how to do this math task. \\
\hline & & I am scared people think I am stupid. \\
\hline & & $\begin{array}{l}\text { I don't know how to make sure that my answers are } \\
\text { correct. }\end{array}$ \\
\hline \multirow{6}{*}{ Bored } & \multirow{3}{*}{ Uninterested } & This math task is boring and I have better things to do. \\
\hline & & $\begin{array}{l}\text { I don't understand what is going on so I don't care } \\
\text { anymore. }\end{array}$ \\
\hline & & This work is too easy and that makes it boring. \\
\hline & \multirow{3}{*}{ Distracted } & I am too hungry/tired to think about maths right now. \\
\hline & & $\begin{array}{l}\text { My friends and I have other more interesting things to } \\
\text { discuss. }\end{array}$ \\
\hline & & $\begin{array}{l}\text { I am getting too hot/cold and that makes it difficult to } \\
\text { concentrate. }\end{array}$ \\
\hline
\end{tabular}

